Abstracta Iranica Abstracta Iranica

Revue bibliographique pour le domaine irano-aryen

Volume 29 | 2008

Comptes rendus des publications de 2006

\title{
Ceramics of the Merv Oasis. Recycling the City. Wainut Greek, Califormia Left Coast Press, 2006, 260 p., 54 fig.
}

\section{Barbara Kaim}

\section{(2) OpenEdition}

Journals

Édition électronique

URL : http://journals.openedition.org/abstractairanica/25532

DOI : 10.4000/abstractairanica.25532

ISSN : 1961-960X

Éditeur :

CNRS (UMR 7528 Mondes iraniens et indiens), Éditions de l'IFRI

\section{Édition imprimée}

Date de publication : 15 mai 2008

ISSN : 0240-8910

Référence électronique

Barbara Kaim, "Ceramics of the Merv Oasis. Recycling the City. Wainut Greek, Califormia Left Coast Press, 2006, 260 p., 54 fig. », Abstracta Iranica [En ligne], Volume 29 | 2008, document 58, mis en ligne le 15 septembre 2008, consulté le 26 septembre 2020. URL : http://journals.openedition.org/ abstractairanica/25532; DOI : https://doi.org/10.4000/abstractairanica.25532

Ce document a été généré automatiquement le 26 septembre 2020.

Tous droits réservés 


\title{
Ceramics of the Merv Oasis. Recycling the City. Wainut Greek, Califormia Left Coast Press, 2006, 260 p., 54 fig.
}

\author{
Barbara Kaim
}

1 Cette présentation des méthodes d'examen de la céramique trouvée pendant les fouilles récentes à Merv (Erk Kala area 1 et Gyaur Kala, area 5) est précédée par une brève histoire des recherches sur les mêmes périodes en Iraq, Iran et à Merv même. L'analyse de la céramique de Merv n'est pas une tâche facile car il s'agit de dépôts secondaires. Pour cette raison l'analyse quantitative a été choisie afin de faire la comparaison proportionnelle de types de poterie entre ces deux ensembles étudiés.

2 Cette approche montre les variations statistiquement significatives entre les deux contextes, entre les textures de pâte et les formes. Ensuite, sont abordées les variations entre les deux ensembles selon l'analyse conventionnelle, qui permettent des indications chronologiques importantes, de même que la mise en évidence de certains types caractéristiques.

\section{INDEX}

Thèmes : 3.1. Est de l'Iran 


\section{AUTEURS}

\section{BARBARA KAIM}

Université de Varsovie 